\title{
LOGÍSTICA REVERSA NA AMAZÔNIA: UM ESTUDO DE CASO EM UMA EMPRESA DO SETOR METALÚRGICO
}

Mayra Oliveira Ramos ${ }^{1}$; Altem Pontes Nascimento²; Suezilde da Conceição Amaral Ribeiro;

Mestranda em Ciências Ambientais, Universidade do Estado do Pará. Email: mayraolramos@gmail.com. Belém-Brasil.

2 Professor(a)/Pesquisador(a) do Mestrado de Ciências Ambientais, Universidade do Estado do Pará.

Recebido em: 08/09/2015 - Aprovado em: 14/11/2015 - Publicado em: 01/12/2015 DOI: http://dx.doi.org/10.18677/Enciclopedia_Biosfera_2015_189

\begin{abstract}
RESUMO
Este estudo teve como objetivo descrever o processo de logística reversa de uma empresa do setor metalúrgico na cidade de Castanhal-PA, relacionando a importância da logística reversa para a empresa e para o meio ambiente. A pesquisa caracteriza-se como um estudo de caso, onde foram utilizadas entrevistas semiestruturadas para coletar os dados com os colaboradores do setor da qualidade da empresa que é o responsável pela logística reversa. Para a análise dos dados, utilizou-se a técnica de análise de conteúdo, e para auxiliar na organização dos dados foi utilizado o software Microsoft Excel 2013. A empresa estudada faz coleta seletiva e dá a destinação adequada aos seus resíduos, excluindo os papéis e orgânicos, pois são dispostos no lixão da cidade, não havendo uma destinação ou disposição adequada dos mesmos. Os resíduos encaminhados para tratamento não retornam à cadeia produtiva, com exceção dos metais pesados onde a empresa busca sempre os reutilizar na fabricação de outros produtos.
\end{abstract}

PALAVRAS-CHAVE: Empresa metalúrgica, Logística reversa, Resíduos sólidos.

\section{REVERSE LOGISTICS IN THE AMAZON: A CASE STUDY ON A METALLURGICAL COMPANY SECTOR}

\begin{abstract}
This study aimed to describe the reverse logistics process of a company in the metallurgical sector in the city of Castanhal-PA, relating the importance of reverse logistics for the company and for the environment. It is characterized as a case study, where were used semi-structured interviews to collect data with employees of the quality sector that is responsible for reverse logistics. For data analysis, we used the content analysis technique, and to help organize the data we used the software Microsoft Excel 2013. The company studied does the selective collection and gives proper disposal its waste, excluding paper and organic, because they are deposited in the city dump, without an appropriate destination or arrangement thereof. However, those waste after referred for treatment, do not return for the productive chain, except for heavy metals where the company always seeks the reuse in the manufacture of other products.
\end{abstract}

KEYWORDS: Metallurgical company, Reverse logistic, Solid waste. 


\section{INTRODUÇÃO}

Com desenvolvimento tecnológico e as constantes inovações surge uma tendência de redução do ciclo de vida dos produtos, acelerando a obsolescência, deixando clara a tendência de descartabilidade dos mesmos (LOURENÇO \& LIRA, 2012). Com isso, ocorre o aumento do volume destinado para aterros, consumo de recursos naturais, energia, poluição do ar, das águas superficiais e subterrâneas, aumento dos custos envolvidos no processo de coleta e destinação dos resíduos (LAGARINHOS \& TENÓRIO, 2013).

As agressões ao meio ambiente são oriundas principalmente dos resíduos industriais, sendo que nestes estão incluídos produtos químicos, metais e solventes químicos que ameaçam os ciclos naturais, pois são amontoados e enterrados, e os gases são lançados no ar, tornando a saúde do ambiente e dos seres vivos ameaçadas (NETO et al., 2014).

O Brasil, Segundo IPEA (2012), apresentou um total de 97.655 .438 toneladas de resíduos sólidos oriundos de indústrias, sendo 3.786 .391 classificados como resíduos perigosos e 93.869.046 como não perigosos. Dados do Inventário de Resíduos Sólidos Industriais afirmam que as indústrias metalúrgicas são as que mais produzem resíduos sólidos, apresentando $42,99 \%$ com relação ao total de resíduos gerados pelas indústrias em geral (FEAM, 2014).

Neste contexto, a busca pela diminuição dos materiais utilizados pelo setor metalúrgico é de fundamental importância, e a implementação de ações efetivas voltadas para a redução do impacto ambiental representam a possibilidade de se atenuar o atual quadro de degradação ambiental presente no país (BRUGGER et al., 2011).

Com a aprovação da Lei oㅜ 12.305, de 2 de agosto de 2010, que instituiu a Política Nacional de Resíduos Sólidos (PNRS), diversos setores produtivos foram obrigados a implementar programas de Logística Reversa (DEMAJOROVIC et al., 2014). A Logística Reversa tem como foco principal garantir o recolhimento e recolocação de bens nos canais de distribuição, gerando dessa forma ganhos econômicos e ambientais, agregando mais valor ao produto (JUNIOR \& SANTOS, 2015). Os programas de Logística Reversa recuperam os resíduos sólidos e transforma-os em matéria-prima, com mitigação dos impactos ambientais e prejudiciais à saúde humana (NETO et al., 2014).

Tais programas têm como objetivo movimentar as mercadorias do local de descarte, a fim de recuperar o seu valor, ou promover a destinação correta dos resíduos (NETO et al., 2014). As operações envolvem um processo de planejamento, execução e controle eficiente dos custos relacionados às matériasprimas, estoque, produtos acabados e informações do ponto de consumo até o ponto de origem dos resíduos, com o objetivo de gerar valor por meio do uso adequado dos recursos e destinação segura (SHERIFF et al., 2012).

A Logística Reversa ainda não é tratada pelas empresas como um importante processo na cadeia logística, e tal fator é evidenciado pelo modo como as empresas lidam com o problema, e em muitos casos não há planejamento para o processo de logística reversa, tornando difícil o controle dos resultados alcançados, consequentemente, impossibilitando na definição de ações para melhorar o fluxo (LOPES et al., 2014).

Com o aumento da geração de resíduos, consequentemente, os locais para o descarte diminuem, tornando a logística reversa como uma alternativa para o gerenciamento ecologicamente correto dos resíduos (LOURENÇO \& LIRA, 2012). Tendo em vista as considerações apresentadas e pela existência de um Sistema de 
Gestão Ambiental (SGA) baseado na norma ISO 14001:2004 na empresa estudada, a pesquisa busca responder os seguintes questionamentos: Como está estruturado processo de logística reversa de uma empresa do setor metalúrgico? Qual a percepção da empresa a respeito da importância da logística reversa nas relações empresa/empresa e empresa/meio-ambiente?

Dessa forma, este estudo teve como objetivo descrever o processo de logística reversa de uma empresa do setor metalúrgico no Estado do Pará, relacionando a importância da logística reversa para a empresa e para o meio ambiente.

\section{MATERIAL E MÉTODOS}

A empresa estudada localiza-se no município de Castanhal-PA situado no Nordeste paraense cuja posição geográfica é determinada pelo paralelo 01017'38"S em sua interseção com o meridiano 47055’35'W (Figura 1). Atua no mercado a mais de 30 anos na linha de fabricação e montagem de estruturas metálicas, com soluções especializadas para clientes de diversos segmentos industriais. Outros campos de atuação da empresa são: a fabricação de equipamentos e usinas para agroindústria, metalúrgica, indústria química e alimentícia, e nos setores de mineração, energia, biodiesel, construção, locação de equipamentos pesados, transportes de máquinas, na área de mineração e no ramo da agroindústria.

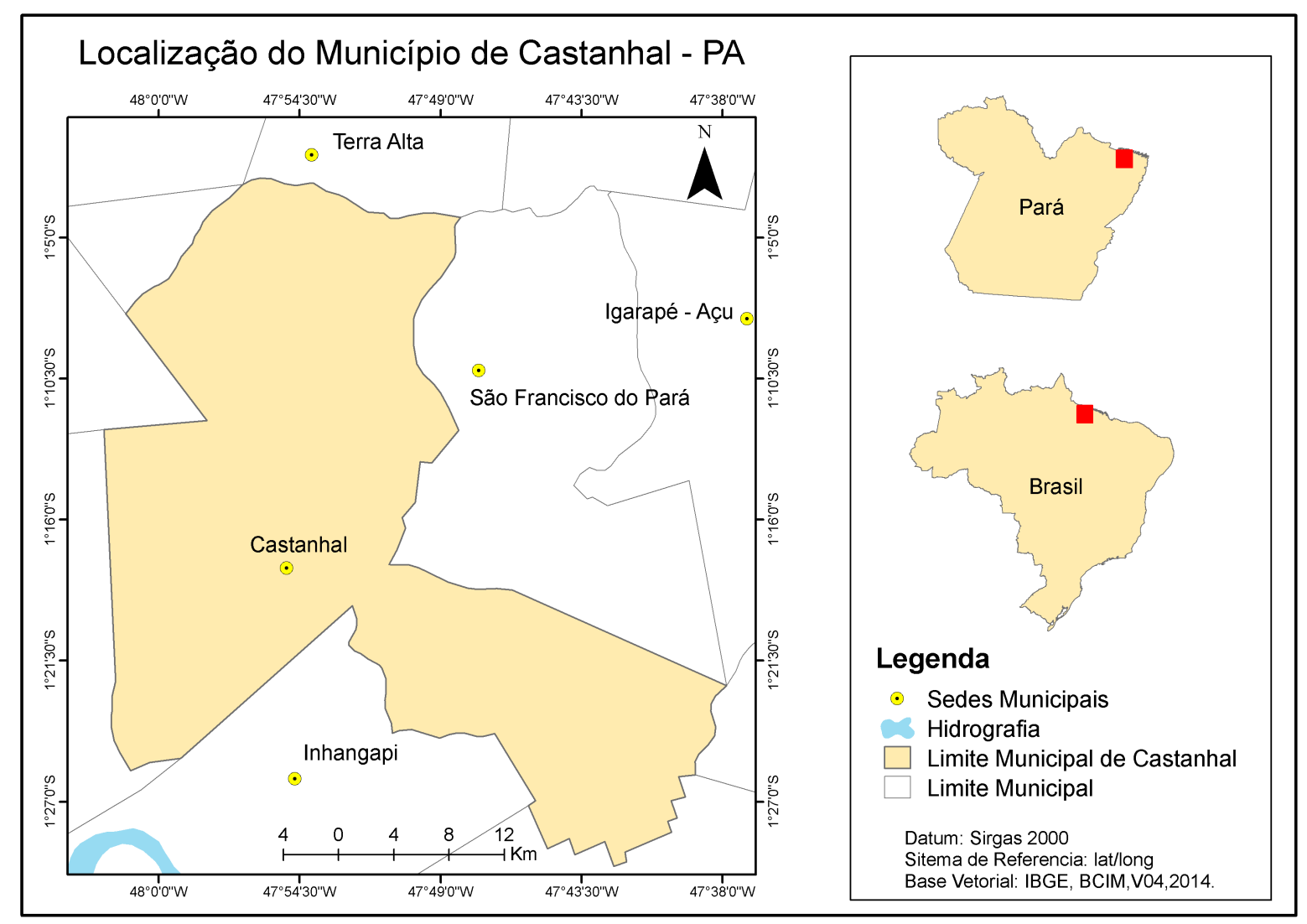

FIGURA 1 - Mapa da localização do munícipio de Castanhal-PA. 
A pesquisa é classificada como básica, exploratória, qualitativa e estudo de caso. Para o levantamento dos dados foram utilizadas entrevistas com a equipe do setor de qualidade que é responsável pela logística reversa da empresa estudada, composta pelo Coordenador do Sistema de Gestão Integrado, Assistente de Meio Ambiente, Assistente de Saúde e Segurança no Trabalho, e dois Inspetores da Qualidade.

As entrevistas são de caráter exploratório, direto, individual e semiestruturadas. Foram realizadas no mês de junho do ano de 2015, na sede da empresa, onde foi possível, além do recolhimento de dados, conhecer a estrutura e o funcionamento geral da logística. O roteiro semiestruturado das entrevistas baseou-se no trabalho desenvolvido por PONTINI (2011), realizando uma adaptação à realidade da empresa e as diferenças entre o processo logístico reverso realizado dentro de uma metalúrgica em contraste à logística reversa no pós-venda do ecommerce abordado no trabalho original. $O$ roteiro possui 15 questões e cada entrevista teve duração média de 30 minutos.

$\mathrm{Na}$ etapa de tratamento dos dados utilizou-se o software Microsoft Excel 2013 para auxiliar na organização dos dados e a técnica de análise de conteúdo que segundo BARDIN (2011) visa obter indicadores (quantitativos ou qualitativos) que permitam a indução de conhecimentos relacionados às condições de produção e recepção destas mensagens, por meio de procedimentos sistemáticos e objetivos de descrição do conteúdo das mensagens. Ainda segundo o autor, a análise de conteúdo possui três fases fundamentais que são:

- Pré-análise: É a fase de organização do material que será analisado.

- Exploração do material: É a segunda etapa e diz respeito à codificação e classificação do material e à definição de categorias de análise.

- Tratamento dos dados: É a última etapa e consiste no tratamento, inferência e interpretação dos resultados. Nela são realizadas a condensação e o destaque das informações a serem analisadas, resultando em interpretações inferenciais. É o momento da intuição, da análise reflexiva e crítica.

Dessa forma, após a etapa de pré-análise, definiram-se as categorias de análise a serem utilizadas juntamente com as unidades de registro, que correspondem às perguntas feitas aos entrevistados. Por último, na fase de tratamento, todas as informações coletadas por meio das entrevistas foram sintetizadas em um conhecimento comum, fazendo parte assim, da unidade de contexto. O Quadro 1 contém as informações referentes às categorias e unidades de registro. Já a unidade de contexto está presente no Quadro 3 que pertence ao tópico Resultados e Discussão. 
QUADRO 1 - Análise de conteúdo (Categorias e Unidade de registro)

\begin{tabular}{|c|c|}
\hline Categorias & Unidade de registro \\
\hline \multirow{9}{*}{$\begin{array}{l}\text { Processos } \\
\text { Logísticos } \\
\text { reversos }\end{array}$} & Como é feita a coleta dos resíduos? \\
\hline & $\begin{array}{l}\text { Quais os produtos que sofrem reaproveitamento/reutilização } \\
\text { /reciclagem? }\end{array}$ \\
\hline & Onde e como é feito o armazenamento dos resíduos? \\
\hline & Qual é destinação destes resíduos? \\
\hline & Qual a destinação dos produtos inservíveis (rejeitos)? \\
\hline & Estes produtos retornam para a cadeia produtiva da empresa? \\
\hline & Como se dá o transporte dos resíduos? \\
\hline & Qual a situação da empresa com relação aos metais pesados? \\
\hline & $\begin{array}{l}\text { São utilizados Equipamentos de Proteção Individual para o } \\
\text { manuseio dos resíduos sólidos? }\end{array}$ \\
\hline \multirow{3}{*}{$\begin{array}{l}\text { Planejamento e } \\
\text { controle dos } \\
\text { processos da } \\
\text { logística reversa }\end{array}$} & Há padronização e mapeamento dos processos reversos? \\
\hline & Há metas e objetivos destinados para a logística reversa? \\
\hline & $\begin{array}{l}\text { Há avaliação da qualidade das atividades reversas? Quais } \\
\text { ferramentas são utilizadas? }\end{array}$ \\
\hline \multirow{3}{*}{ Ética ambiental } & $\begin{array}{l}\text { A empresa tem conhecimento da existência de leis e normas } \\
\text { que orientam sobre destinação ou disposição final } \\
\text { ambientalmente adequada? }\end{array}$ \\
\hline & $\begin{array}{l}\text { Há algum órgão público que fiscalize a geração de resíduos } \\
\text { sólidos? }\end{array}$ \\
\hline & $\begin{array}{l}\text { A empresa acredita que a logística reversa além te trazer } \\
\text { benefícios ao meio ambiente também pode trazer rentabilidade } \\
\text { ao negócio? }\end{array}$ \\
\hline
\end{tabular}

\section{RESULTADOS E DISCUSSÃO}

A empresa estudada faz coleta seletiva de todos os resíduos gerados pela empresa, que são: plásticos, papéis, orgânicos, varrição, madeira, sucatas residuais de processos produtivos (metais) e de materiais perigosos. Os resíduos perigosos gerados são: tintas, óleos, graxas e lâmpadas, por exemplo.

No que diz respeito ao armazenamento, todos os plásticos, papéis, orgânicos, varrição e madeira estão armazenados em uma área chamada de "área de resíduos" e ficam mantidos em contêineres. De acordo com a Lei 12.305/2010 que trata da Política Nacional dos Resíduos Sólidos (PNRS), estes são classificados como resíduos não perigosos.

A Figura 2 apresenta os contêineres onde são armazenados os resíduos de madeira, plástico, papel, varrição, metal e orgânico, sendo que cada um possui uma coloração diferente para facilitar a identificação. 


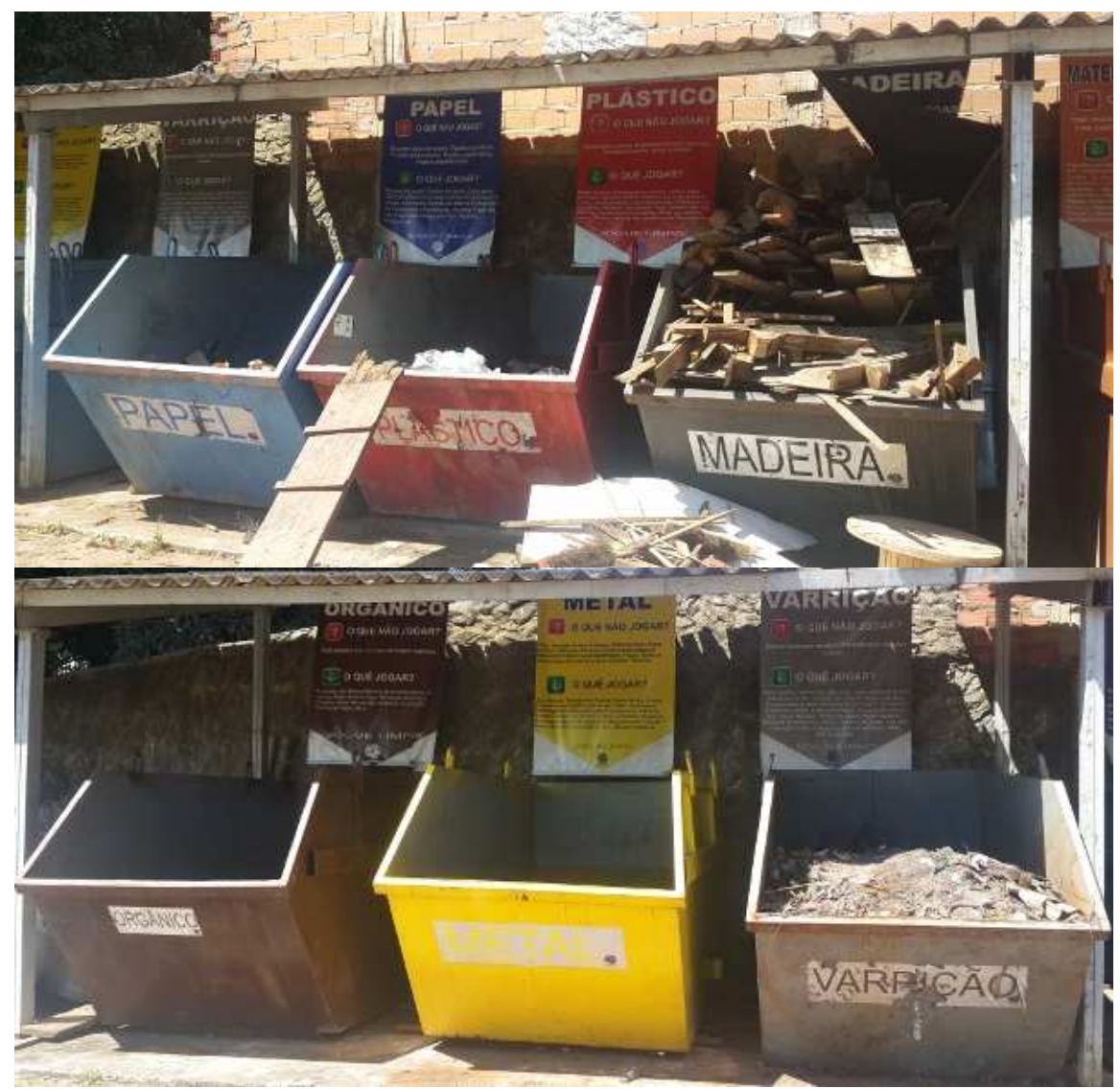

FIGURA 2 - Contêineres de armazenamento.

Fonte: Autores.

Os metais que são resíduos dos processos produtivos ficam mantidos em contêineres que estão presentes em cada setor gerador deste tipo de resíduo. As estruturas metálicas mais robustas e pesadas são armazenadas em um pátio a céu aberto, demarcadas por uma tela de aço alaranjada.

Os metais pesados são armazenados sem que seja feito um controle de estoque dessas peças, não se conhece a quantidade de peças, as informações identificadoras que caracterizam cada uma, como diâmetro, largura, altura, e nem a data em que esses materiais foram armazenados nesse local. Isso dificulta no momento de localização dessas peças para serem reutilizadas, fazendo com que, muitas vezes, sejam esquecidas, pois demanda muito tempo. A Figura 3 mostra o local onde os metais pesados ficam mantidos.

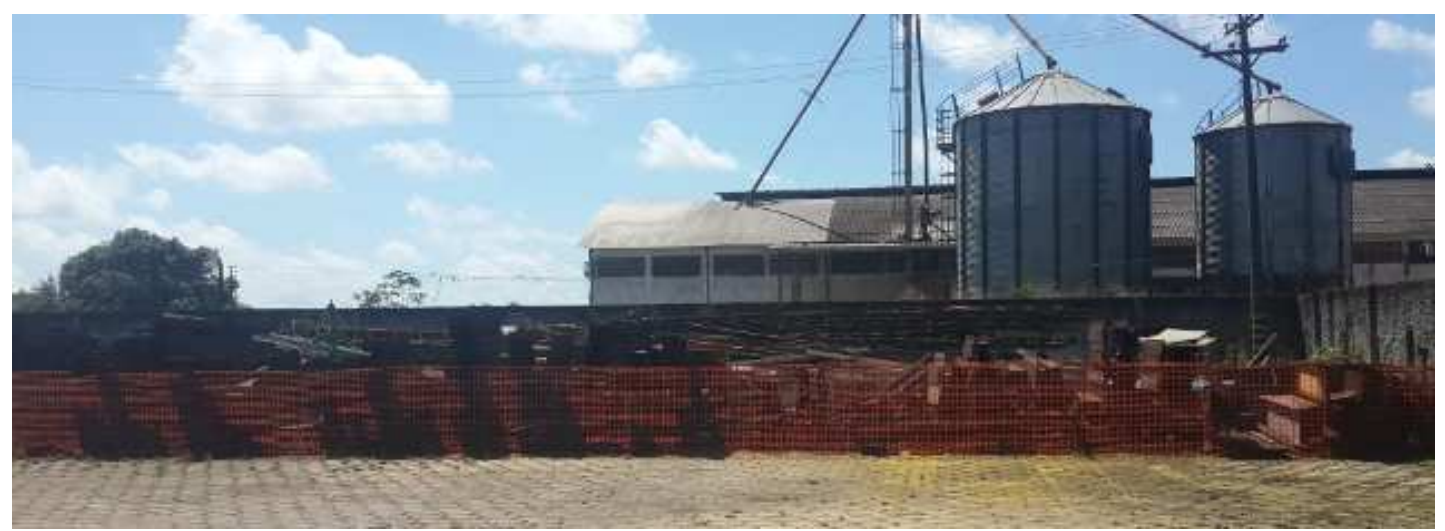

FIGURA 3 - Localização metais pesados

Fonte: Autores. 
No trabalho desenvolvido por AMAOMO et al. (2014) a empresa metalúrgica estudada reutiliza os resíduos de metais gerados nos processos produtivos e usa como matéria-prima secundária, a fim de reduzir custos. Isso mostra que a logística reversa causa não só benefícios para o meio ambiente como também para a rentabilidade e lucratividade da empresa.

Os óleos (material perigoso) ficam mantidos em tambores em uma área delimitada por paredes de tijolos e coberta por telhado. A Figura 4 mostra o local onde os óleos são depositados, sendo que há uma preocupação da empresa também no tipo de óleo utilizado, pois são sempre os biodegradáveis. A NBR 12.235 de 1992 discorre sobre o procedimento correto para armazenamento de resíduos perigosos, que segundo a NBR 10.004 de 1987 são aqueles resíduos que se enquadram em pelo menos um dos critérios de periculosidade (inflamabilidade, corrosividade, reatividade, toxicidade, patogenicidade) (ABNT, 1992).

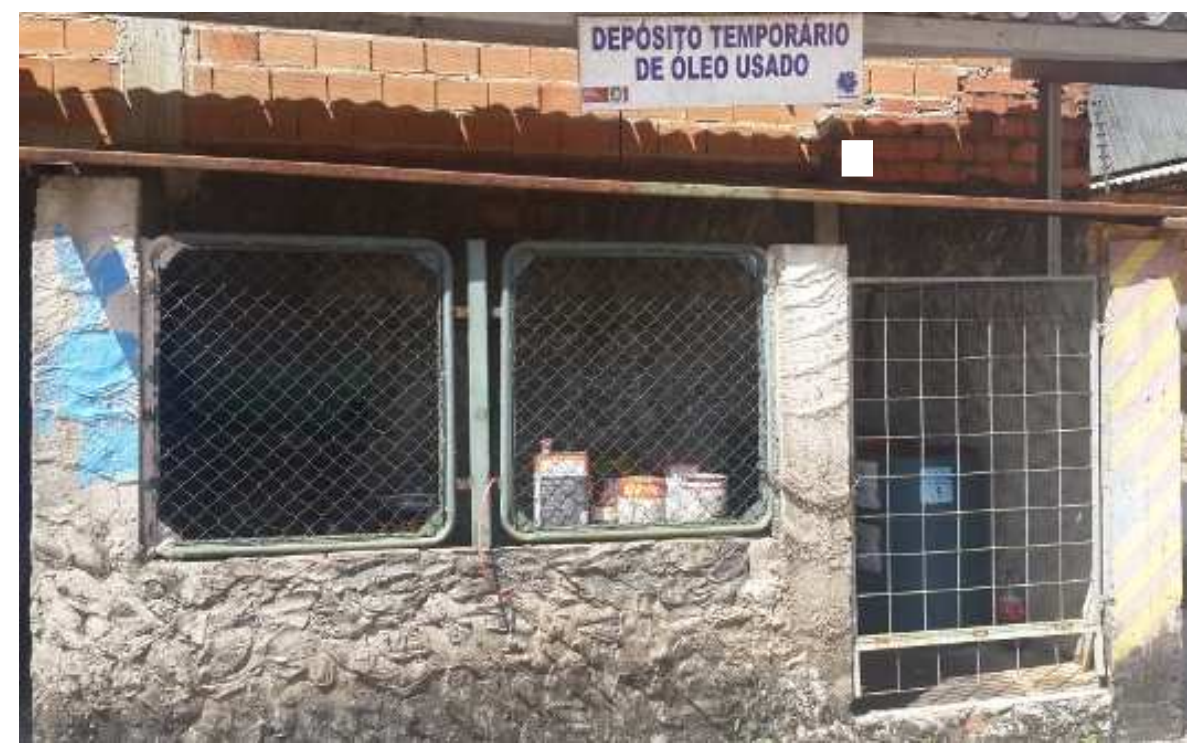

FIGURA 4 - Local de armazenamento de óleos.

Fonte: Autores.

As tintas ficam em uma área afastada, dentro do setor de pintura, mantidas em suas embalagens originais, local considerado improvisado pela empresa, já que estão fora das especificidades de armazenamento ditadas pela NBR 12.235, onde este tipo de material precisa estar armazenado em contêineres, tambores, tanques ou granel e em um local coberto, com ventilação, piso impermeável e estar devidamente identificado (ABNT, 1992).

As lâmpadas são armazenadas no próprio almoxarifado em caixas de papelão, em uma área demarcada específica. A NBR 12.235 rege que as lâmpadas inservíveis devem ser embaladas novamente, se possível na embalagem original, senão utilizar papelão, e armazená-las em local seco, mantendo cuidado para que não quebrem e o mercúrio presente seja lançado no ambiente (ABNT, 1992). No estudo realizado por JÚNIOR et al. (2013), as lâmpadas inservíveis da empresa estudada são armazenadas em latões e caixas de metal a céu aberto, expostos ao sol e chuva, não ainda acondicionados em prateleiras adequadas, possuindo uma grande quantidade de material que fica em contato com o solo e os funcionários.

No que diz respeito a destinação, os resíduos orgânicos, papeis e varrição são recolhidos diariamente pelo município e depositados no lixão da cidade. Não é ENCICLOPÉDIA BIOSFERA, Centro Científico Conhecer - Goiânia, v.11 n.22; p.2168 
realizado tratamento para que estes sejam reciclados, por este motivo, são considerados rejeitos. No caso da madeira e do plástico, a metalúrgica paga para que a empresa Cerâmica Tropical e Selma Reciclagem, respectivamente, coletem estes materiais.

Os metais são doados para a Sucataria Vasconcelos para que estes possam reutilizar estes resíduos. Já os metais pesados são armazenados para serem posteriormente reutilizados. E os resíduos perigosos, que são as tintas, os óleos e as lâmpadas, são coletados pelos próprios fornecedores desses produtos duas vezes por semana, sendo estes os responsáveis pelo seu tratamento. A empresa estudada aponta ainda que estas empresas terceirizadas possuem certificação para atuar nessas áreas. A Figura 5 sumariza as informações citadas acima, identificando os tipos de resíduos e qual o destino após armazenamento.

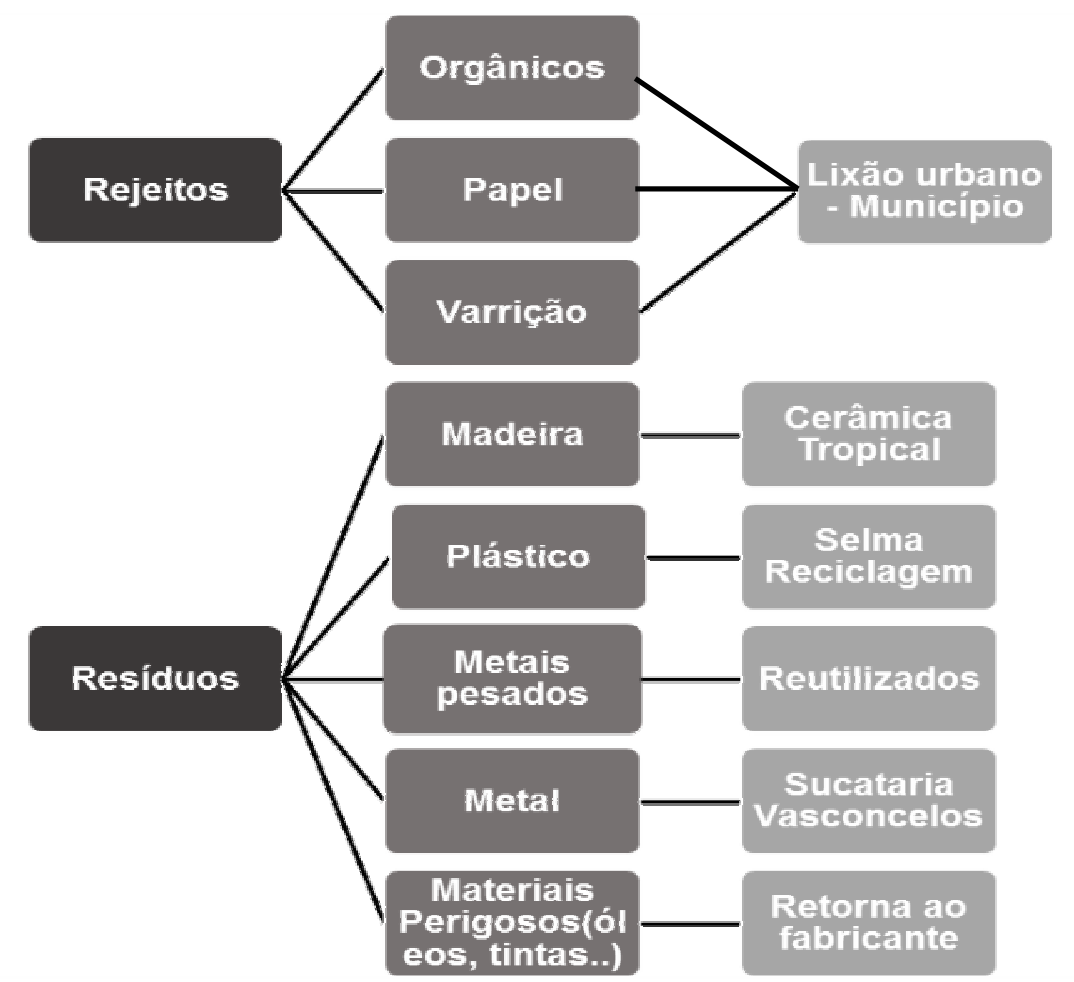

FIGURA 5 - Destinação dos resíduos e rejeitos.

Fonte: Autores.

O ciclo da logística reversa não é realizado por completo, já que seria necessário que estes resíduos retornassem ao processo produtivo, o que não acontece. Os resíduos possuem uma destinação ambiental adequada. Identificou-se que há ações dentro da empresa voltadas ao planejamento e controle da produção dos resíduos sólidos. Por exemplo, a empresa utiliza indicadores que expressam a quantidade de resíduos que são gerados, contribuindo para o mapeamento dos processos da logística reversa.

A empresa também possui uma meta de produzir apenas $5 \%$ de resíduos referente ao faturamento total do que é produzido, e quando essa porcentagem é extrapolada, é realizado um plano de ação a fim de investigar o que provocou este problema através da ferramenta 5W2H. POLACINSKI et al. (2013) descreve que a ferramenta $5 \mathrm{~W} 2 \mathrm{H}$ consiste num plano de ação para atividades pré-estabelecidas que precisem ser desenvolvidas com a maior clareza possível, além de funcionar como um mapeamento dessas atividades. 
A empresa possui Certificação de Sistema de Gestão Ambiental com a ISO 14001 e isso auxilia na obtenção e detenção de informações necessárias que regulamentam a gestão e gerenciamento dos resíduos sólidos. Anualmente, a empresa passa por auditoria a fim de renovar a certificação, e por isso busca sempre pela adequação às leis e normas. Também realiza o Inventário de Resíduos que é somado ao Sistema Declaratório Anual de Resíduos Sólidos. Segundo o Art. 8o da Lei 12.305 estes são instrumentos da PNRS (BRASIL, 2010 a).

De acordo com o Art. 71 do Decreto 7.404 o Sistema Nacional de Informações Sobre a Gestão dos Resíduos Sólidos (SINIR), coordenado pelo Ministério do Meio Ambiente (MMA), tem como um dos objetivos disponibilizar periodicamente o diagnóstico da situação dos resíduos sólidos no país, através do Inventário Nacional Resíduos Sólidos (BRASIL, 2010 b).

A empresa demonstra interesse em fazer com que os resíduos retornem à cadeia produtiva, como no caso dos metais, pois vê na logística reversa uma importância que vai além da ambiental. Reconhece também que a redução na fonte e o reaproveitamento trazem benefícios econômicos, reduzem custos e consequentemente aumentam o lucro. Porém, ainda procura por fornecedores que sejam capazes de dar o tratamento correto a esses resíduos e retorná-los ao ciclo dos produtos da metalúrgica.

O Quadro 2 apresenta a matriz da análise de conteúdo contendo todas as informações coletadas por meio das entrevistas. Na primeira coluna estão as categorias já apresentadas na metodologia que facilitaram o entendimento e extração dos resultados. Na segunda coluna estão as unidades de registro que apresentam as perguntas utilizadas na entrevista, e na terceira estão as unidades de contexto que sintetizam todas as respostas dos entrevistados contribuindo para uma melhor análise dos dados.

QUADRO 2 - Matriz da análise de conteúdo.

\begin{tabular}{|c|c|c|}
\hline Categorias & Unidades de registro & Unidades de contexto \\
\hline \multirow{3}{*}{$\begin{array}{l}\text { Processos } \\
\text { Logísticos } \\
\text { reversos }\end{array}$} & $\begin{array}{l}\text { Como é feita a coleta dos } \\
\text { resíduos? }\end{array}$ & $\begin{array}{l}\text { Existem lixeiras para coleta seletiva } \\
\text { dentro de cada setor da empresa. }\end{array}$ \\
\hline & $\begin{array}{l}\text { Quais os produtos que sofrem } \\
\text { reaproveitamento/reutilização } \\
\text { /reciclagem? }\end{array}$ & $\begin{array}{l}\text { Metais, madeira, varrição, orgânicos } \\
\text { papel, plástico e resíduos perigosos } \\
\text { (óleos, graxas, tintas e lâmpadas). }\end{array}$ \\
\hline & $\begin{array}{l}\text { Onde e como é feito o } \\
\text { armazenamento dos } \\
\text { resíduos? }\end{array}$ & \\
\hline 4 & OSFERA, Centro Científico Conhe & 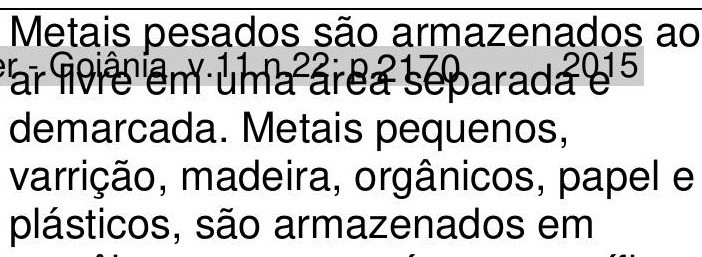 \\
\hline
\end{tabular}




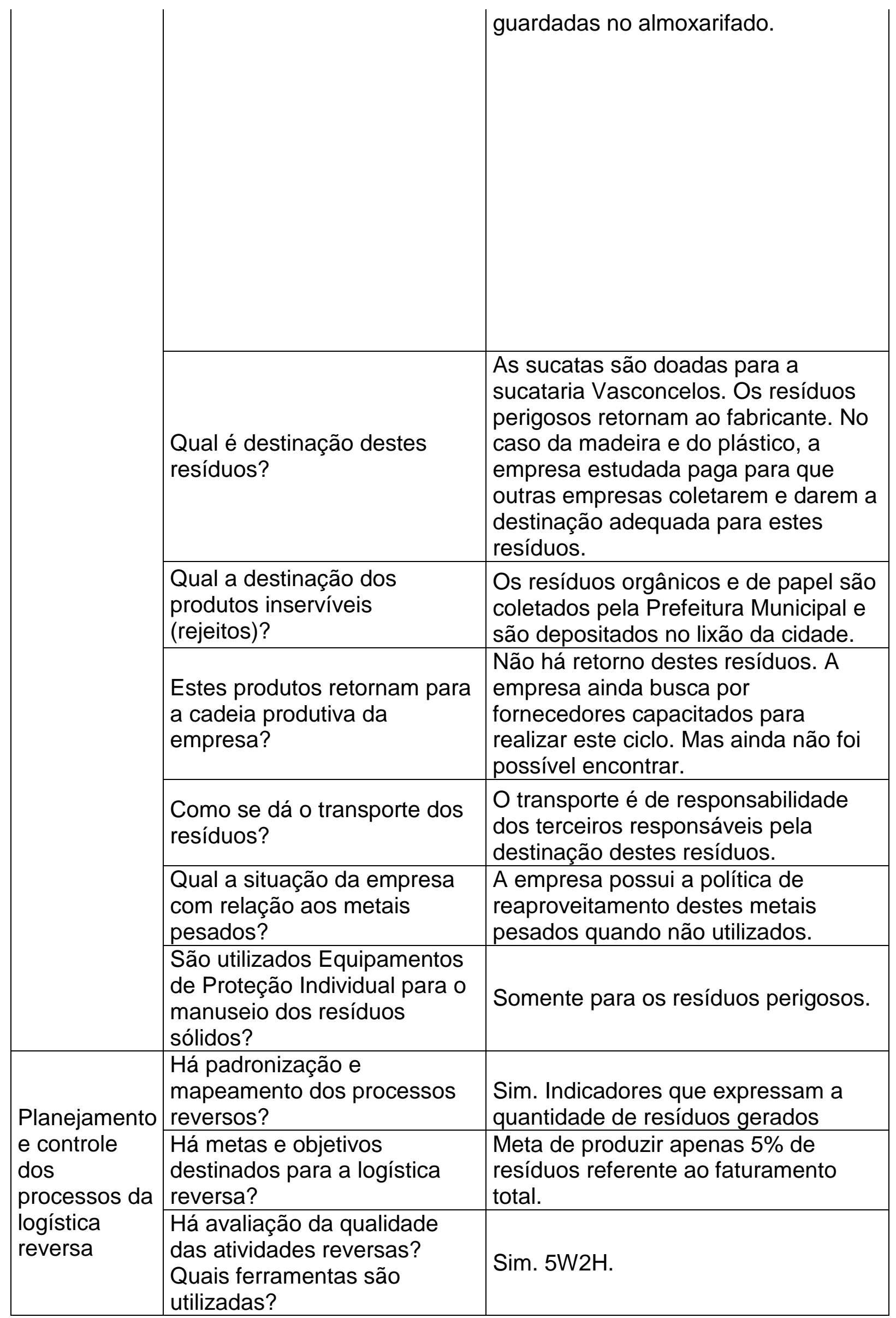




\begin{tabular}{|c|c|c|}
\hline \multirow{3}{*}{$\begin{array}{l}\text { Ética } \\
\text { ambiental }\end{array}$} & $\begin{array}{l}\text { A empresa tem conhecimento } \\
\text { da existência de leis e normas } \\
\text { que orientam sobre } \\
\text { destinação ou disposição final } \\
\text { ambientalmente adequada? }\end{array}$ & $\begin{array}{l}\text { Sim, a empresa possui certificação } \\
\text { ambiental (ISO 14000) e possui } \\
\text { conhecimento sobre as legislações e } \\
\text { normas regentes sobre o assunto. }\end{array}$ \\
\hline & $\begin{array}{l}\text { Há algum órgão público que } \\
\text { fiscalize a geração de } \\
\text { resíduos sólidos? }\end{array}$ & $\begin{array}{l}\text { Sim, anualmente é realizado o } \\
\text { inventário de resíduos e enviado ao } \\
\text { SINIR (Sistema Nacional de } \\
\text { Informações sobre a Gestão dos } \\
\text { Resíduos Sólidos). A Secretaria } \\
\text { Municipal de Meio Ambiente também } \\
\text { fiscaliza as atividades de logística } \\
\text { reversa }\end{array}$ \\
\hline & $\begin{array}{l}\text { A empresa acredita que a } \\
\text { logística reversa além te } \\
\text { trazer benefícios ao meio } \\
\text { ambiente também pode trazer } \\
\text { rentabilidade ao negócio? }\end{array}$ & $\begin{array}{l}\text { Sim, tem-se o objetivo de poder } \\
\text { reutilizar os outros resíduos assim } \\
\text { como é feito com os metais. } \\
\text { Infelizmente ainda não foram } \\
\text { encontradas empresas capazes de } \\
\text { dar o tratamento adequado aos } \\
\text { resíduos e fazer com que eles } \\
\text { possam retornar à cadeia produtiva, } \\
\text { mas sabe-se o quanto é vantajoso em } \\
\text { termos financeiros para a empresa, } \\
\text { isso é vivenciado com a reutilização } \\
\text { dos metais. }\end{array}$ \\
\hline
\end{tabular}

\section{CONCLUSÃO}

A logística reversa precisa se expandir ainda mais na indústria metalúrgica estudada. Ainda que a gestão da empresa tenha demonstrado possuir conhecimento acerca dos benefícios da logística reversa, há uma falta de articulação entre os diversos atores envolvidos, pois é importante que haja o retorno dos resíduos tratados à cadeia produtiva para que a rentabilidade econômica seja maior e os impactos ambientais menores.

\section{REFERÊNCIAS}

ABNT - ASSOCIAÇÃO BRASILEIRA DE NORMAS TÉCNICAS. NBR 12235: Armazenamento de resíduos sólidos perigosos. Rio de Janeiro, 1992.

AMAOMO et al. Logística Reversa nas Metalúrgicas. In: SIMPOSIO DE EXCELÊNCIA EM GESTÃO E TECNOLOGIA, 6., 2014, Rio de Janeiro. Gestão do Conhecimento para Sociedade. Rio de Janeiro, 2014.

BARDIN, L. Análise de conteúdo. Lisboa: Edições 70, 2011.

BRASIL. Lei no 12.305, de 2 de agosto de 2010.Institui a Política Nacional de Resíduos Sólidos; Altera a Lei no 9.605, de 12 de fevereiro de 1998; E dá outras providências. Diário Oficial República Federativa do Brasil, Brasília, DF, 2 ago. $2010 . \quad$ Disponível em: < http://www.planalto.gov.br/ccivil 03/ ato20072010/2010/lei/l12305.htm>. Acesso em: 13 jul. 2015. 
Decreto-lei no7.404, de 23 de dezembro de 2010. Regulamenta a Lei no 12.305, de 2 de agosto de 2010, que institui a Política Nacional de Resíduos Sólidos, cria o Comitê Interministerial da Política Nacional de Resíduos Sólidos e o Comitê Orientador para a Implantação dos Sistemas de Logística Reversa, e dá outras providências. Diário Oficial República Federativa do Brasil, Brasília, DF, 23 dez. 2010. Disponível em:< http://www.planalto.gov.br/ccivil 03/ ato20072010/2010/Decreto/D7404.htm>. Acesso em: 22 jul. 2015.

BRUGGER, P. et al. Produção mais limpa um estudo teórico sobre sua importância no contexto ambiental e econômico e sua aplicabilidade na visão da ecologia profunda. Revista Educação Ambiental em Ação. issn 1678-0701. n, 38, 2011.

DEMAJOROVIC, J.; CAIRES, E. F.; GONÇALVES, L, N. S.; SILVA, M. J. C. Integrando empresas e cooperativas de catadores sem fluxos reversos de resíduos sólidos pós-consumo: o caso Vira-Lata. Cad. EBAPE.BR, v. 12, p. 514-532, 2014.

FEAM (Fundação Estadual do Meio Ambiente). Inventário de Resíduos Sólidos. Belo Horizonte, 2014.

IPEA (Instituto de Pesquisa Econômica Aplicada). Diagnóstico dos Resíduos Sólidos Indústriais, Brasília, 2012.Disponível em: <http://www.ipea.gov.br/portal/index.php?option=com content\&view=article\&id=1562 1\&ltemid=7. Acesso em: 15 mar. 2015.

JÚNIOR et al. Estudo De Caso: Coleta e Logística Reversa para Lâmpadas Fluorescentes no Município de Franca, SP. Revista Eletrônica em Gestão, Educação e Tecnologia Ambiental. v (10), no 10, p. 2091-2101, 2013.

JUNIOR, S. S. B.; SANTOS, R. B. M. Ganhos Ambientais com a Prática da Logística Reversa no Varejo Supermercadista. Revista Espacios, v. 36, n. 5, p. 14, 2015.

LAGARINHOS, C. A. F.; TENÓRIO, J. A. S. Logística Reversa de pneus usados no Brasil. Polímeros, v.23, n.1, p. 49-58, 2013.

LOPES, D. M. M.; D'AGOSTO, M. A.; FERREIRA, A. F.; OLIVEIRA, C. M. Improving post-sale reverse logistics in department stores: a Brazilian case study. Journal of transportation Literature. v. 8, n. 2, pp.325-348, 2014.

LOURENÇO, J. C.; LIRA, W. S. Logística Reversa: Uma análisecomparativa entre três processos reversos de residues vítreos. REUNIR: Revista de Administração, Contabilidade e Sustentabilidade, v.2, n.4, p.19-34, 2012.

NETO, G. C. D.; SOUZA, M. T. S.; SILVA, D.; SILVA, L. A. Avaliação das vantagens ambientais e economicas da implantação da logística reversa no setor de vidros impressos. Ambiente e Sociedade, v. 17, n. 3, p. 199-220, 2014.

POLACINSKI et al. Implantação dos $5 S$ s e proposição de um SGQ para uma indústria de erva-mate. Revista ADMpg Gestão Estratégica, Ponta Grossa, v. 6, n. 1, p.71-78, 2013. 
PONTINI, J. Logística reversa: um estudo do pós-venda no e-commerce da empresa x. 2011. 113 p. Trabalho de Conclusão de Curso (Bacharelado em Administração). Universidade Federal do Rio Grande do Sul, Porto Alegre, 2011.

SHERIFF, K.; GUNASEKARAN, A.; NACHIAPPAN, S. Reverse logistics network design: a review on strategic perspective. International Journal of Logistics Systems and Management, v.12, n.2, p. 171-194, 2012. 